ORIGINAL ARTICLE

\title{
Seasonality of type 1 diabetes mellitus in children and its modification by weekends and holidays: retrospective observational study
}

\author{
J A Mooney, P J Helms, I T Jolliffe, P Smail, on behalf of the Scottish Study Group for the Care of \\ Diabetes in the Young
}

Arch Dis Child 2004;89:970-973. doi: 10.1136/adc.2003.040865

See end of article for
authors' affiliations
$\ldots \ldots \ldots \ldots \ldots \ldots \ldots \ldots$
Correspondence to:
Professor P J Helms,
Department of Child
Health, University of
Aberdeen, Royal
Aberdeen Children's
Hospital, Westburn Road,
Aberdeen AB25 2ZG,
Scotland, UK; p.j.helms@
abdn.ac.uk
Received
12 December 2003
Accepted for publication
8 January 2004

\begin{abstract}
Background: Diagnoses of type 1 insulin dependent diabetes mellitus are generally more common in winter, although this seasonal pattern has not been observed in children of preschool age ( $0-4$ years) or in all countries.

Aims: To confirm the persistence of seasonality and the influence of age, holidays, and weekends. Methods: We extracted data on date of birth, date of presentation, age, and sex of children diagnosed with diabetes and registered with the Scottish Study Group for the Care of Diabetes in the Young. Cosinor analysis was applied to monthly and mid-monthly data. Two sample $Z$ tests were used to compare the epochs 1984-1992 and 1993-2001.

Results: Some 4517 children between 0 and 14 years of age (2407 male and 2110 female) presented with IDDM between 1 January 1984 and 31 December 2001. Seasonality was evident in children above 4 years of age with amplitudes of $19.5-25.7 \%$ and peaks between mid December and mid January. Presentation was strongly influenced by weekends and holiday periods, with reduced presentations in December compared with November and January, and with the lowest presentations in July (the main Scottish holiday month). Using mid-month to mid-month data did not change the overall seasonality but did improve the fits for cosinor analysis. Mondays and Fridays were the most common days for presentation.

Conclusion: Initial presentation of IDDM in Scotland follows a stable seasonal pattern in all but the youngest children with lower rates of presentation in holiday periods and at weekends for all age groups.
\end{abstract}

$\mathrm{S}$ easonal patterns in the onset of type 1 insulin dependent diabetes mellitus (IDDM) in children have previously been noted, although not in all studies. In a study of Scottish data over the period 1984-1993, a marked seasonal pattern in the onset of IDDM was found in children aged between 5 and 9 years. ${ }^{1}$ Using cosinor analysis it was noted that the peak incidence for this group occurred in December and the lowest in July, with an amplitude of $28 \%$. Significant seasonality was observed in children aged 10-14 years, although this was less obvious than in those aged 5-9 years. No significant seasonal pattern was found in children aged 0-4 years. However such seasonality is not universal as no seasonal pattern was found in Japanese children aged between 0 and 14 years over the period $1986-1990^{2}$ nor in the Baltic states for the years 1983-1992. ${ }^{3}$ In view of this lack of agreement and the possible distortion of the data by delayed presentation during holiday periods and at weekends, we sought to clarify these issues using the Scottish Study Group for the Care of Diabetes in the Young dataset.

\section{METHODS}

Data on date of birth, date of onset, age, and sex of children diagnosed with IDDM between 1984 and 2001 were obtained from the Scottish Study Group for the Care of Diabetes in the Young, a comprehensive prospective dataset into which data on all affected children presenting to paediatric units in Scotland are entered. Data were analysed using the same methods and age groups as previously reported ${ }^{1}$ : namely 0 4 years, 5-9 years, and 10-14 years. Cosinor analysis was applied to monthly data. ${ }^{45}$ To eliminate any variation due to differing month length, the data were month corrected to
31 days by multiplying the February figure by 1.097 and the 30 day months by 1.033 . The results from cosinor analysis give the amplitude (the distance of the peak above the mean level, expressed as a percentage), the acrophase (the position in the year of the peak), and a p value indicating the significance of the seasonal pattern. In order to take into account any distortion of month by month seasonality due to the winter and summer holiday seasons mid-month to midmonth data were also used, again month corrected to 31 days. In order to assess whether any observed patterns were consistent over time, two sample Z tests were used to compare the epochs 1984-1992 and 1993-2001.

\section{RESULTS}

Over the 18 year period, 4517 children aged between 0 and 14 years presented with IDDM. The initial presentations made in each calendar month over the whole period failed to demonstrate any evidence of seasonality for children aged 0-4 years in contrast to those aged 5-9 years and 10-14 years (fig 1). Cosinor analysis confirmed these impressions with non-significant seasonality in the youngest age group but with evidence of seasonality in the two older age groups although this was not consistent across all gender/age groups (table 1). However, as can be seen from fig 1 , the number of presentations in December tended to be lower than in the adjacent months of November and January. It was also apparent that in three of the gender/age groups July, the main holiday month in Scotland, exhibited the lowest number of presentations (fig 1). When mid-month to mid-month data

Abbreviations: IDDM, insulin dependent diabetes mellitus 

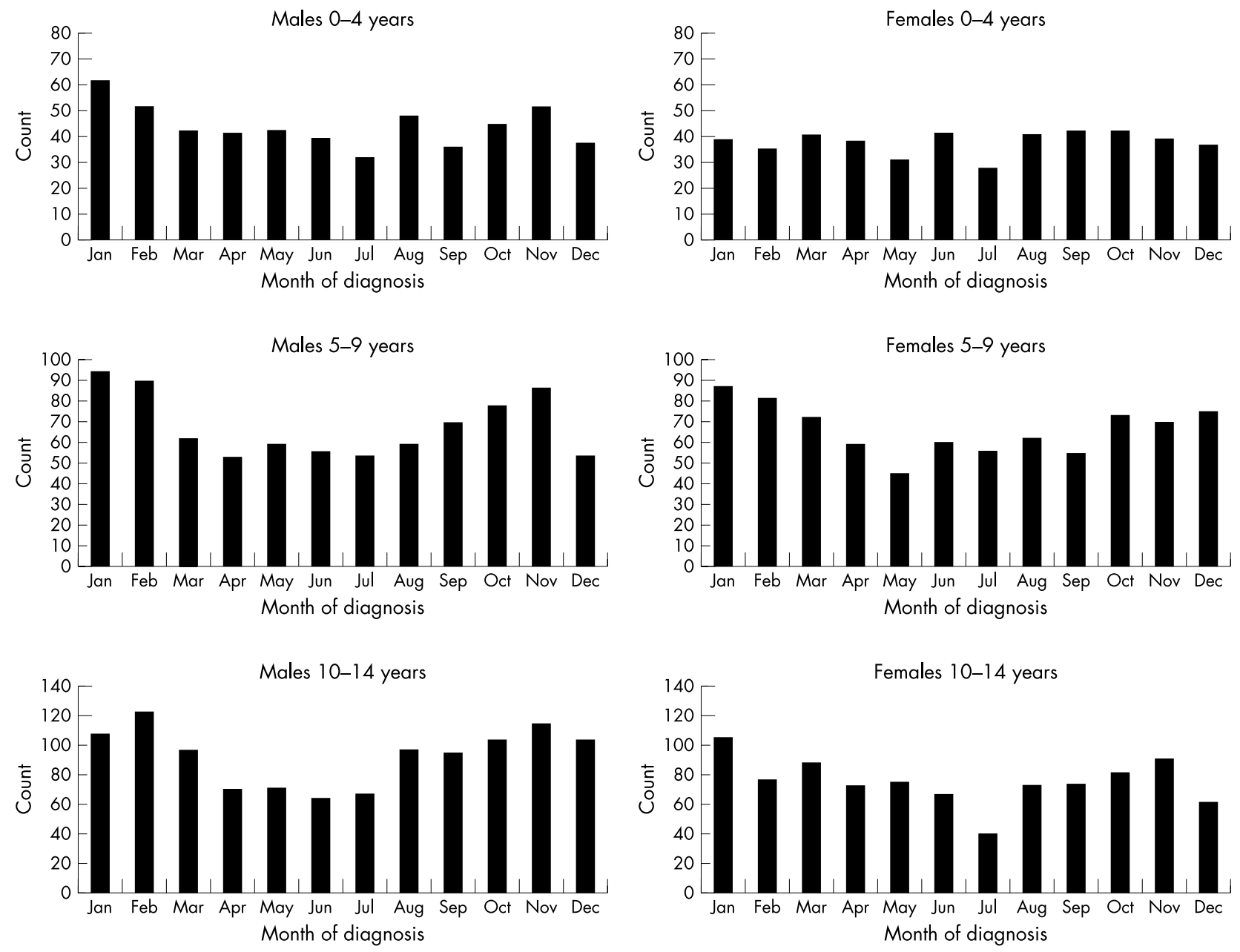

Figure 1 Monthly diabetes diagnoses by age groups and sex, 1984-2001.
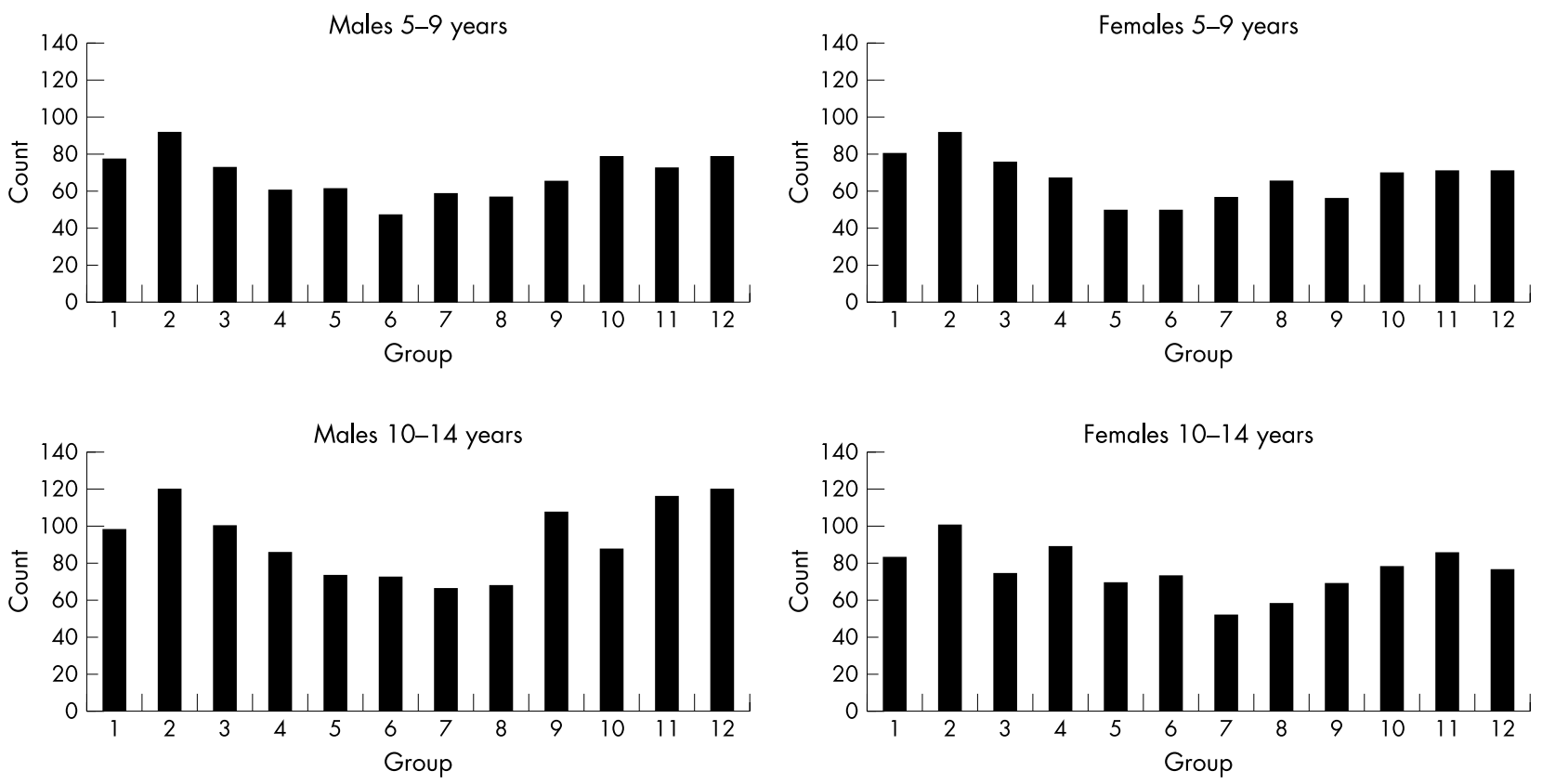

Figure 2 Diabetes diagnoses using the groups from table 1. 
were used in place of calendar month, the lack of seasonality remained in the youngest age group (data not shown), although a more consistent and significant pattern emerged in the older two age groups (fig 2 and table 2). Dividing the data into two time periods, 1984-1992 and 1993-2001, the amplitude of seasonal variability was almost identical in the two periods $(22.1 \%, 21.9 \%)$. However, the peak occurrence (acrophase) was later in the second period (6th January) than in the first (7th December). As cosinor analysis is a form of regression analysis, an approximate $\mathrm{Z}$ test can be constructed to test the significance (or otherwise) of this difference in the acrophase. The $\mathrm{p}$ value for this test between the two time epochs was approximately 0.02 .

As a depression of presentations similar to that in holiday periods could also be operating at weekends, we compared actual presentations to those expected if occurrence was uniform throughout the week. For such an even distribution, $28.57 \%$ of all presentations would be expected over weekends. This was clearly not the case as can be seen from fig 3 where actual weekend presentations for 1984-1992 and 1993-2001 were $12.35 \%$ and $11.38 \%$, respectively. These values were significantly lower than the $28.57 \%$ expected $(p<0.0001$, one sample $\mathrm{Z}$ test using a normal approximation to the binomial distribution), and with no significant difference between the percentage of weekend presentations in each period $(p=0.07$, two sample $\mathrm{Z}$ test). Mondays and Fridays were the most common days for presentation in both periods with approximately $40 \%$ of all presentations falling on these 2 days. Unlike the lack of seasonality observed in the youngest age group (0-4 years), age did not appear to influence the weekday/weekend pattern of presentation (data not shown).

\section{DISCUSSION}

Presentation of IDDM in Scottish children exhibits a seasonal pattern, except in children aged less than 4 years. More diagnoses are made in the winter months, although the number of presentations in December is lower than in adjacent months. The lower rates in December could be explained by the reduction in specialist and non-emergency services over the holiday period with a subsequent "catch up" in January, or by a reluctance of parents to seek medical help and invite disruption to their family routine during holiday periods. The dip in July presentations, which corresponds to the Scottish school holidays, would favour the latter rather than the former explanation although some of the reduction in July could be accounted for by families taking their holidays outside Scotland. Taking these possible distortions of the true seasonal pattern into account by grouping from mid-month to mid-month resulted in an even clearer seasonal pattern which was easier to model using cosinor analysis (fig 2).

In the whole data set there was no evidence of seasonality for date of birth $(p=0.121)$. Furthermore, the amplitude of $4 \%$ and the peak in mid May were very similar to the nonsignificant seasonality of all live births in Scotland for the period 1983-2000 which had an amplitude of 4\% and which

Table 1 Results of cosinor analysis on original data

\begin{tabular}{lccll}
\hline Group & Sample size & Amplitude (\%) & Acrophase & p Value \\
\hline 0-4 Male & 519 & 15.1 & 7 January & 0.137 \\
0-4 Female & 447 & 6.3 & 8 November & 0.482 \\
5-9 Male & 798 & 20.9 & 17 December & 0.063 \\
5-9 Female & 779 & 21.2 & 1 January & 0.003 \\
10-14 Male & 1090 & 25.7 & 12 December & 0.001 \\
10-14 Female & 1663 & 19.5 & 9 January & 0.117 \\
\hline
\end{tabular}

Table 2 Cosinor analysis using mid-month data

\begin{tabular}{|c|c|c|c|c|}
\hline Group & Sample size & Amplitude (\%) & Acrophase & $p$ Value \\
\hline 5-9 Male & 798 & 21.5 & 16 December & 0.002 \\
\hline 5-9 Female & 779 & 21.6 & 27 December & 0.005 \\
\hline 10-14 Male & 1090 & 25.6 & 11 December & 0.002 \\
\hline 10-14 Female & 1663 & 18.8 & 11 January & 0.012 \\
\hline
\end{tabular}

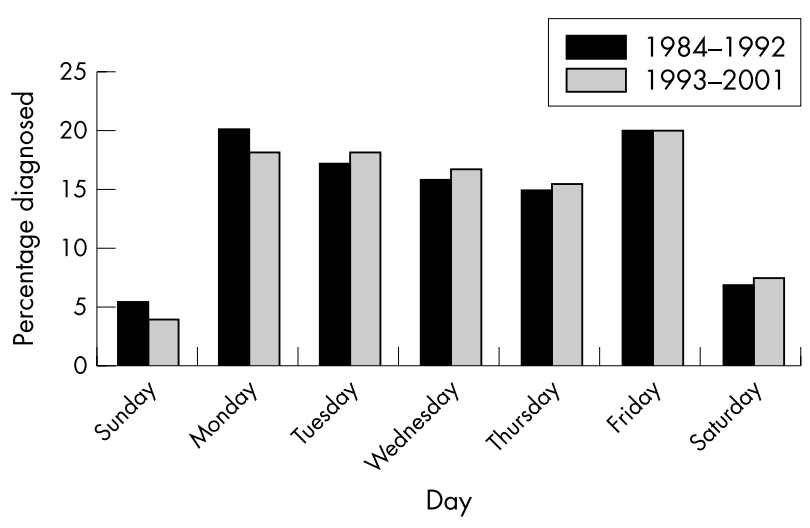

Figure 3 Weekend effect by period.

showed annual peaks between mid May and August (data not shown but available on request).

Fewer presentations of diabetes at weekends compared to during weekdays might be expected for the same reasons outlined above. Despite the changes in access to medical services at weekends that have occurred over the period of assessment, the observation that the pattern of weekend presentations has not changed suggests that the explanation may lie in the use of health services rather than their availability. Presentation of IDDM is a process in which noticeable symptoms of IDDM can vary in their timing and their severity. Some symptoms of intermittent hyperglycaemia may occur for up to a year, ${ }^{6}$ whereas thirst and polyuria caused by sustained hyperglycaemia may take more than 13 weeks before progressing to diabetic ketoacidosis. ${ }^{7}$ However there was no suggestion in our data, in contrast to a previous report, ${ }^{7}$ that the pattern of weekday presentation was influenced by season. The biphasic pattern of presentation intensity with peaks on Mondays and Fridays would be consistent with parents either trying to get their children seen before the weekend or, if the child became ill over the weekend, waiting until Monday before seeking medical help. This pattern of referral is likely to be followed for many other subacute conditions and could potentially adversely affect outcome. Distortions such as this and the effects of holiday periods need to be accounted for when studying the seasonality of subacute diseases.

\section{ACKNOWLEDGEMENTS}

We thank all clinicians and specialist nurses contributing to the Scottish Study Group for the Care of Diabetes in the Young for their commitment to the dataset and to Professor Norman Waugh for his perceptive comments and support.

\footnotetext{
Authors' affiliations

J A Mooney, I T Jolliffe, Department of Mathematical Sciences, University of Aberdeen, Scotland, UK

P J Helms, Department of Child Health, University of Aberdeen, Royal Aberdeen Children's Hospital, Aberdeen, Scotland, UK

P Smail, Royal Aberdeen Children's Hospital, Aberdeen, Scotland, UK

Conflict of interest: none declared.
} 


\section{REFERENCES}

1 Douglas S, McSporran B, Smail P. Seasonality of presentation of type I diabetes mellitus in children. Scott Med J 1999;44:41-6.

2 Kida K, Mimura G, Ito T, et al. Incidence of Type 1 diabetes mellitus in children aged 0-14 in Japan, 1986-1990, including an analysis for seasonality of onset and month of birth: JDS study. Diabet Med 2000;17:59-63.

3 Padaiga $Z$, Tuomilehto J, Karvonen $M$, et al. Seasonal variation in the incidence of Type 1 diabetes mellitus during 1983 to 1992 in the countries around the Baltic Sea. Diabet Med $1999 ; 16: 736-43$
4 Halberg F, Johnson EA, Nelson W, et al. Autorhythmometry - procedures for physiological self-measurements and their analysis. Physiol Teacher 1972;1:1-11

5 Douglas AS, Al-Sayer H, Rawles JM, et al. Seasonality of disease in Kuwait. Lancet 1991;337:1393-7.

6 Tarn AC, Smith CP, Spencer KM, et al. Type I (insulin dependent) diabetes: a disease of slow clinical onset? $\mathrm{Br}$ Med J 1987;294:342-5.

7 Ludvigsson J, Afoke AO. Seasonality of type 1 (insulin dependent) diabetes mellitus: values of C-peptide, insulin antibodies and haemoglobin Alc show evidence of a more rapid loss of insulin secretion in epidemic patients. Diabetologia 1989;32:84-91.

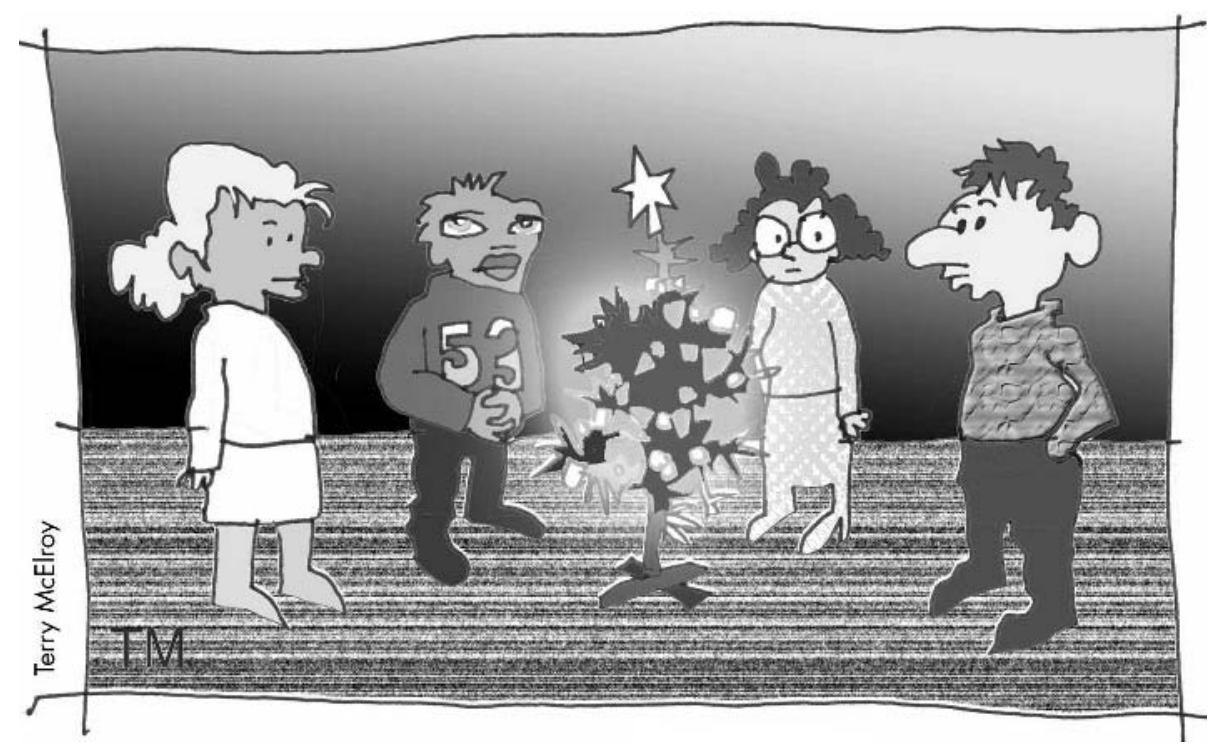

